\title{
TOXICOLOGICAL EVALUATION OF VEGETABLE OILS AND BIODIESEL IN SOIL DURING THE BIODEGRADATION PROCESS
}

\author{
Ivo S. Tamada, Renato N. Montagnolli, Paulo R. M. Lopes, Ederio D. Bidoia*
}

Departamento de Bioquímica e Microbiologia, Instituto de Biociências, Universidade Estadual Paulista, Rio Claro, SP, Brasil.

Submitted: May 03, 2011; Returned to authors for corrections: October 12, 2011; Approved: June 07, 2012.

\begin{abstract}
Vegetable oils and their derivatives, like biodiesel, are used extensively throughout the world, thus posing an environmental risk when disposed. Toxicity testing using test organisms shows how these residues affect ecosystems. Toxicity tests using earthworms (Eisenia foetida) are widespread because they are a practical resource for analyzing terrestrial organisms. For phytotoxicological analysis, we used seeds of arugula (Eruca sativa) and lettuce (Lactuca sativa) to analyze the germination of seeds in contaminated soil samples. The toxicological experiment was conducted with four different periods of biodegradation in soil: zero days, 60 days, 120 days and 180 days. The studied contaminants were soybean oil (new and used) and biodiesel (B100). An evaluation of the germination of both seeds showed an increased toxicity for all contaminants as the biodegradation occurred, biodiesel being the most toxic among the contaminants. On the other hand, for the tests using earthworms, the biodiesel was the only contaminant that proved to be toxic. Therefore, the higher toxicity of the sample containing these hydrocarbons over time can be attributed to the secondary compounds formed by microbial action. Thus, we conclude that the biodegradation in soil of the studied compounds requires longer periods for the sample toxicity to be decreased with the action of microorganisms.
\end{abstract}

Key words: bioremediation, toxicity, soybean oil, soil.

\section{INTRODUCTION}

Vegetable oils have been presented as possible energy sources since the end of the nineteenth century. However, this alternative only gained focus after the petroleum crisis in the 1970s. Currently, with the growing environmental concern for the contamination and degradation of ecosystems, energy sources with more ecological appeal emerge as alternatives to nonrenewable resources with higher pollution potential (19). Thus, the biodiesel alternative emerges, being both a renewable and environmentally viable energy source. Its viability is mainly due to the fact that it is produced from vegetable oils or animal fats through the transesterification process (17).

In this context, the EU intends to increase the rate at 
which alternative fuels are used in road traffic in order to reduce dependence on crude oil imports, reach the goals of the Kyoto Protocol, and support the agriculture sector (19).

Currently the production and use of alternative energy sources have increased a lot in Brazil. In 2008 the country produced approximately 5.7 million tons of soybean oil and in 2010 a total of 1.8 billion liters of biodiesel should be produced from soybean oil (4).

The increased consumption of vegetable oils turned them into compounds with high pollution potential. In order to properly treat the environments contaminated by hydrocarbons, bioremediation is an efficient, low cost and environmentally viable process. This process is based on the microbial potential to metabolize persistent compounds (2).

Landis and $\mathrm{Yu}(9)$ observed that many organisms possess the ability to degrade toxic substances, and it is possible to use this ability to remove xenobiotics from the environment through their physiological systems. Thus, the microbiota acts in the decomposition of organic compounds by biodegradation. Finally, the microbial degradation often promotes mineralization of the compounds. Therefore, the final products are water, carbon dioxide and biomass $(8,2,13)$.

Along with bioremediation, toxicological studies also emerge as important instruments to develop technologies for properly treating contaminated environments. The numerous biodegradation processes in natural environments have produced a range of testing and analysis (15), such as the ecotoxicity studies, which aim to obtain efficient products capable of minimally affecting the environment.

Thus, there is the example of assessing the toxicity of the soil using earthworms (Eisenia foetida), which is described in the ministry of interior manual of tests for evaluation of ecotoxicity of chemical agents (5). International standards for toxicity tests using E. foetida are also described by Liu et al. (10) and also by the Organization for Economic Cooperation, the guide to test No. 207 (14).

Risk assessment and toxicity tests provide a rational basis for making decisions regarding public health and for taking the necessary actions to reduce or eliminate the risk of contamination (16).

According to Landis and $\mathrm{Yu}(9)$ toxicology related to the environment can be analyzed considering three functions: interaction of the chemical compound (xenobiotics) with the environment, the site of its action, and its effects on higher levels of biological organization.

Therefore, tests of acute and chronic toxicity become of great importance since they enable us to answer questions about the toxicity of a chemical compound under different conditions and their effects on living organisms.

Seed germination is part of the phytotoxicological analysis and represents an important practical test, due to its reduced cost and reasonable sensitivity in indicating the presence of toxic or biological inhibitors (12). According Wang and Keturi (20) and Lopes et al. (12) seeds of Lactuca sativa (lettuce) appear to be quite efficient because lettuce is a sensitive test-organism and has a high germination rate, as does Eruca sativa (arugula).

In the biodegradation of organic compounds generate secondary compounds, this study aimed to determine the toxicity of soil contaminated with soybean oil (new and used) and biodiesel according to the biodegradation process ( 0,60 , 120 and 180 days).

\section{MATERIALS AND METHODS}

\section{Material}

The soil used in the toxicity bioassays was the sandy type (grain size of $0.59 \mathrm{~mm}$ to $1.0 \mathrm{~mm}$ ) collected under the Technical Standard L6.245 - "Soils - Collection and sample preparation - Procedures" (7).

The compounds studied in the biodegradation and toxicity tests were: vegetable soybean oil Lisa Cargill ${ }^{\circledR}$ (soybean oil), vegetable soybean oil Lisa Cargill ${ }^{\circledR}$ used for frying (used soybean oil) and new biodiesel / B100 produced by Caramuru Alimentos $^{\circledR}$ ("biodiesel"). Biodiesel has citric acid and tertbutilhidroquinona (TBHQ) compounds between $10 \mathrm{mgL}^{-1}$. 
The equipment used were: analytical scale Chyo ${ }^{\circledR}$ - Model JK200; semi-analytical scale Gehaka ${ }^{\circledR}$ - Model BG440; germination chamber BOD Marconi ${ }^{\circledR}$ - Model MA403, pipettes, plastic bags, beakers, glass rod and mesh sizes of 1.00, 0.59 and $0.35 \mathrm{~mm}$.

For toxicity tests three testing organisms were used: seeds of Eruca sativa (arugula), seeds of Lactuca sativa (lettuce) and specimens of Eisenia andrei (earthworms).

\section{Methods}

First, it was necessary to establish the concentration of oil to be biodegraded in the soil for the toxicity testing. This concentration should provide an average toxicity for all compounds and for all the used testing organisms. In order to determine this concentration, a pre-test was carried out, using the following volumes of oil per $100 \mathrm{~g}$ of soil: $0.5 \mathrm{~mL}, 1.0 \mathrm{~mL}$, $5.0 \mathrm{~mL}$ and $10.0 \mathrm{~mL}$.

Since the concentrations of $0.5 \mathrm{~mL}$ and $1.0 \mathrm{~mL}$ showed no significant variation in toxicity to the control, Table 1 shows only the data generated from concentrations of $5.0 \mathrm{~mL}$ and 10.0 $\mathrm{mL}$. Table 1 shows that the concentration of $7.5 \mathrm{~mL}$ oil/100 g soil would allow tests of toxicity without causing total inhibition of test organisms in E. sativa and L. sativa. For E. andrei the concentration of $7.5 \mathrm{~g} \mathrm{~mL}$ oil/100 caused no deaths without bio-degradation.

Thus, this concentration was used for biodegradation tests.

Table 1. Preliminary test to determine the proportion of oil in $100 \mathrm{~g}$ soil for use in toxicity assays

\begin{tabular}{ccccc}
\hline & & \multicolumn{3}{c}{$\%$ of inhibition or deaths } \\
\hline compound & volumn & E. sativa & L. sativa & E. andrei \\
\hline soy oil & $5 \mathrm{~mL}$ & 10 & 20 & 0 \\
& $10 \mathrm{~mL}$ & 23.3 & 26 & 0 \\
used soy oil & $5 \mathrm{~mL}$ & 23.3 & 30 & 0 \\
& $10 \mathrm{~mL}$ & 16.6 & 40 & 0 \\
biodiesel & $5 \mathrm{~mL}$ & 46.6 & 50 & 0 \\
& $10 \mathrm{~mL}$ & 56.6 & 80 & 0 \\
\hline
\end{tabular}

The contaminated sample submitted to biodegradation in the soil was composed of: $7.5 \mathrm{~mL}$ oil, $0.15 \mathrm{~mL}$ of chemical surfactant (Tween $80^{\circledR}$ ), $6.25 \mathrm{~mL}$ of distilled water in $100 \mathrm{~g}$ soil. These proportions were based on Lopes and Bidoia (11) and Montagnolli et al. (13).

For the biodegradation process to occur, microorganisms that are potential bio-degraders must contact the contaminated soil. Soils containing soybean oil (new and used) and biodiesel were conserved in plastic bags containing several holes of 1.0 $\mathrm{mm}$ diameter and these were buried at $15 \mathrm{~cm}$ below the surface according to Lopes and Bidoia (11) and Montagnolli et al. (13). This allowed the flow of microorganisms between the sample and the external environment, and the soil microorganisms capable of metabolizing these hydrocarbons came into contact with the oils.
Toxicity tests were carried out using $1,200 \mathrm{~g}$ of the sample contaminated with different compounds. This amount was divided for three toxicological tests (150 g for E. sativa, $150 \mathrm{~g}$ for L. sativa and $900 \mathrm{~g}$ for E. andrei). This procedure was repeated for each contaminant and control.

After 0, 60, 120 and 180 days of biodegradation, the bags were dug out to evaluate the toxic effect of contaminants. The test organisms were placed in contact with the soil at different incubation times for three days for the seeds of Eruca sativa, five days for the seeds of Lactuca sativa and seven days for Eisenia andrei.

Note that each toxicity test related to a period of biodegradation was prepared for four samples: control (no oil), new soybean oil, used soybean oil and biodiesel. Thus, four plastic bags were reserved for biodegradation at time zero and, 
similarly, another set of four bags was reserved for each biodegradation time (t0, t60, t120 and t180).

Germination tests using seeds of E. sativa and L. sativa were based on Lopes et al. (12) and adjustments were performed in triplicate with 10 seeds in each replicate.

According to Lopes et al. (12), germination tests consider the contaminant as follows: toxic when germination inhibition occurred above $40 \%$; starting toxicity when the inhibition of germination occurred between $10 \%$ and $40 \%$; and not toxic when presenting inhibition up to $10 \%$.

However, in tests using seeds of L. sativa, the germination was not satisfactory in the control test (80\%). Therefore, the data of Latuca sativa were corrected by adapting the formula of Abbott (1). This equation allows measuring the effectiveness of an insecticide in percentage and in this case it will be used to determine the toxicity of the environmental contaminant in inhibiting the germination of $L$. sativa. The formula is described as: $\% I=((C-T) \times 100) / C$, where $\% I$ is the percentage of inhibition, $C$ represents the number of germinated seeds in the control and $T$ represents the number of germinated seeds in the treatment.

In addition to tests of germination, the tests of severe toxicity using Eisenia andrei were also carried out in triplicate using 10 worms in each replica. These tests were based on Brazil (5), Liu et al. (10) and Lopes et al. (12).

\section{RESULTS AND DISCUSSION}

The toxicological test with E. sativa (Figure 1) revealed a starting toxicity ( $10 \%$ to $40 \%$ inhibition) at t0 for all contaminants. At t60, soy oil continued exhibiting starting toxicity, but biodiesel had increased its toxic effect (inhibition above $40 \%$ ). At t120, the used soybean oil showed trace of toxicity, but the new soybean oil and biodiesel were both toxic, the latter with greater inhibition of seed germination. Finally, at t180 all contaminants presented inhibition rates above $40 \%$; the largest toxic effect was found in biodiesel (around 90\%) and the used soybean oil had the lowest effect (40\%).

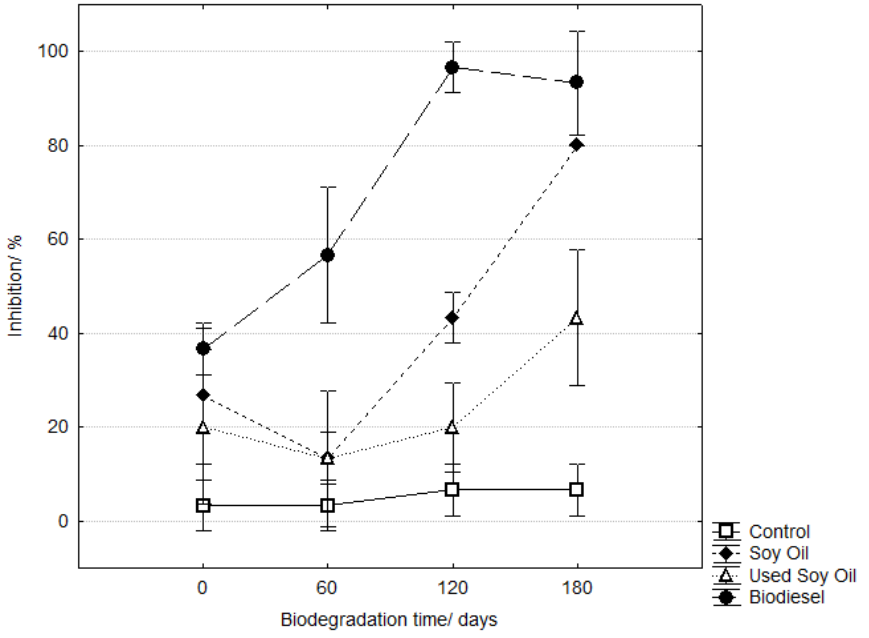

Figure 1. Germination inhibition of Eruca sativa's seeds in soils incubated for $0,60,120$ and 180 days.

The results for tests with seeds of $L$. sativa are shown in Figure 2. They differ from those found for E. sativa (Figure 1). At time zero (t0) soybean oil proved to be non-toxic, with inhibition of germination below $10 \%$, while biodiesel presented toxicity. At t60, soybean oil showed medium toxicity and biodiesel remained toxic. At t120, soybean oil still showed signs of toxicity and biodiesel promoted further inhibition of germination of L. sativa reaching about $70 \%$. At t180, the used vegetable oil showed $40 \%$ inhibition of seed germination, soybean oil again proved to be toxic (above $40 \%$ inhibition) and biodiesel produced $100 \%$ inhibition.

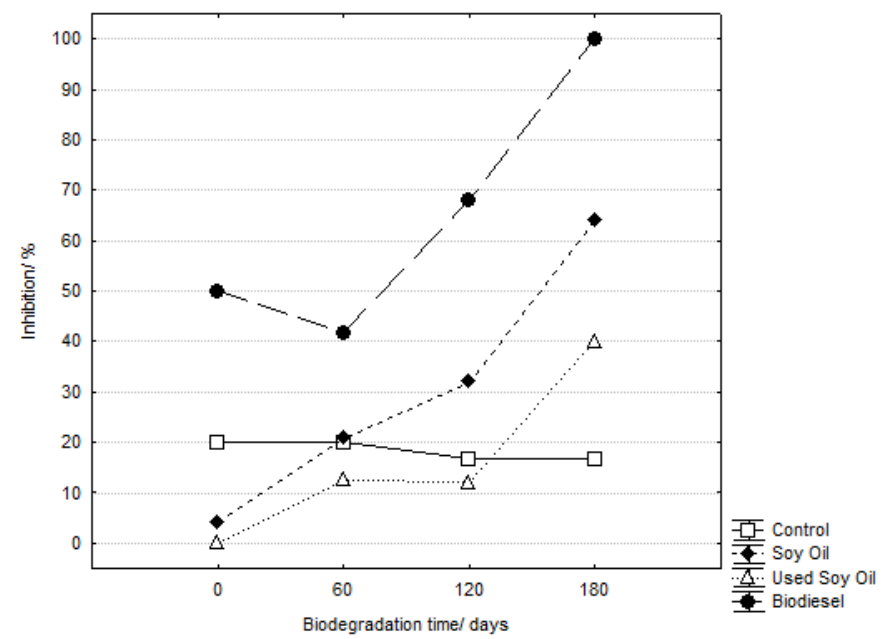

Figure 2. Germination Inhibition of Lactuca sativa's seeds in soils incubated for $0,60,120$ and 180 days. 
The results of the toxicity test with Eisenia andrei showed that only biodiesel remained toxic during the biodegradation process (Figure 3). Although at t0, biodiesel demonstrates little toxic effect, its toxicity increased significantly during biodegradation, reaching $100 \%$ mortality.

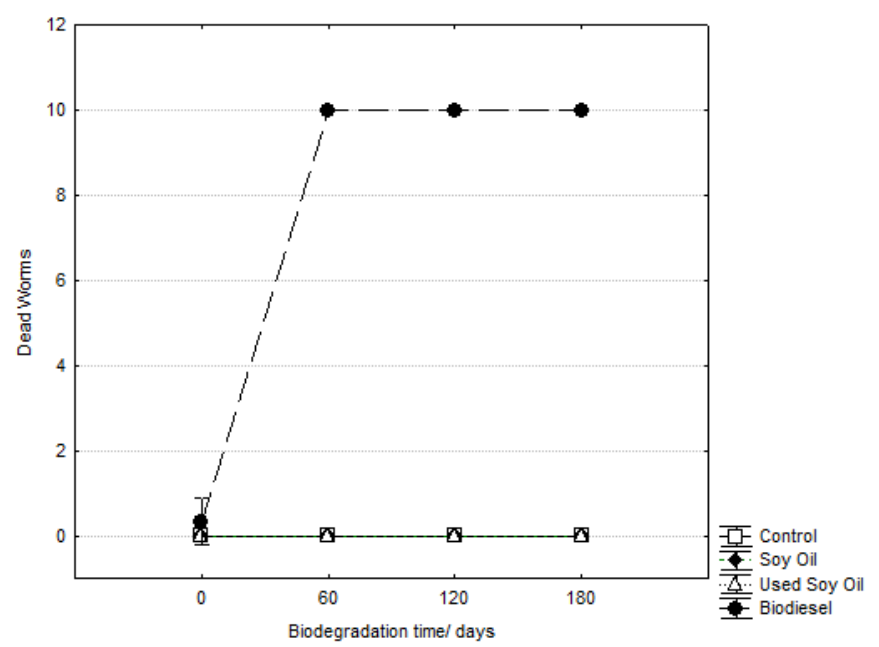

Figure 3. Death of Eisenia andrei in soils incubated for 0, 60, 120 and 180 days.

Figure 4 presents the changes in mass of earthworms ( $E$. andrei) during the biodegradation of vegetable oils and biodiesel, negative values corresponding to weight lost and “-100\%" corresponding to death of earthworms. In soybean oil, earthworms gained weight, especially during the final phase of biodegradation. This fact shows a higher intake by these organisms as the compound is biodegraded, proving also that vegetable oils and the secondary compounds formed during their degradation were nontoxic to E. andrei.

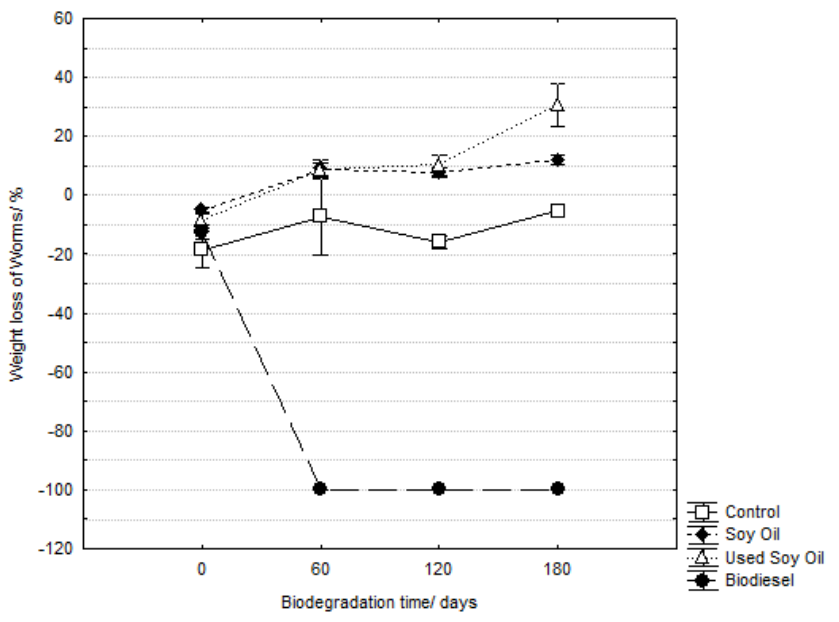

Figure 4. Percentage of weight loss in worms (E. andrei) in soils incubated for $0,60,120$ and 180 days.
According to Montagnolli et al. (13) and Ramalho and Jorge (18), industrialized vegetable oils present antioxidants added for conservation such as citric acid and third-butyl hydroquinone (TBHQ). TBHQ is heat resistant and has high stability therefore it is widely used in oil industry (18).

The presence of antioxidants in the composition can probably complicate microbial action and even confer toxicity to living things (3). Synthetic antioxidants such as butyl-hydroxyanisole (BHA) and butyl-hydroxytoluene (BHT) have been reported to be mutagenic and carcinogenic, so there is a rigorous rule for their use in foods (6).

The toxicity presented by the vegetable oils can be attributed to secondary compounds formed due to biodegradation in soil. For biodiesel, besides the secondary compounds due to degradation, TBHQ can give an increase in toxicity, a fact noted in the evaluation with the E. andrei (Figure 3).

\section{CONCLUSION}

Biodiesel was the most toxic among the treatments, although a similar toxicity to soybean oil was expected, because of the similar biological training. The toxicity of the treatments is especially due to the formation of secondary compounds during biodegradation and, for biodiesel, the presence of TBHQ after initiation of biodegradation. In phytotoxicological tests there was an increase in toxicity in all treatments over time, especially for biodiesel, which showed higher toxic levels. Biodiesel is the only that showed toxicity for E. andrei. In general, biodiesel was the most toxic followed by new soybean oil and then the soybean oil used. Biodegradation provided a temporary increase in toxicity for the plants and also for biodiesel in the test with E. andrei, showing that the time for biodegradation of these materials in soil should be greater than what was sampled.

\section{ACKNOWLEDGEMENTS}

The authors thank FUNDUNESP, Hélio Hermínio Checon, Luiz Motohissa Yojo and Angela Satiko Yojo.

\section{REFERENCES}

1. Abbott, W.S. (1925). A method for computing the effectiveness of an 
insecticide. J. Econ. Entomol. 18, 265-267.

2. Alexander, M. (1999). Biodegradation and Bioremediation. Academic Press, San Diego.

3. Aluyor, E.; Oboh, I.; Okieimen, C. (2009). The effect of tertiary butyl hydroquinone on the biodegradability of palm olein. Leonardo El. J. Pract. Technol. 14, 47-56.

4. Amaral, D.F. (2009). Demystification of the national program for the production and use of biodiesel - A review of the Brazilian vegetable oil industry. ABIOVE, São Paulo.

5. Brazil (1988). Evaluation of the toxicity to soil organism: earthworms Eisenia foetida. In: Manual of tests for evaluation the ecotoxicology of chemical agents. Ministry of interior- Special secretary of environment, Brasília, pp. D5.1-7.

6. Botterweck, A.A.M.; Verhagen, H.; Goldbohm, R.A.; Kleinjans, J.; Van den Brandt, P.A. (2000). Intake of butylatedhydroxyanisole and butylatedhydroxytoluene and stomach cancer risk: results from analyses in the Netherlands Cohort Study. Food. Chem. Toxicol. 38 (7), 599-605.

7. CETESB - Environmental Sanitation and Technology Company (1984). Soils- Collection and Sample Preparation - Procedure.Technical Standard L6.245, São Paulo, Brazil.

8. Eweis, J.B.; Ergas, S.J.; Chang, D.P.Y.; Schroeder, E.D. (1998). Bioremediation principles.WCB/McGraw-Hill, Malaysia.

9. Landis, W.G.; Yu, Ming-Ho. (1995). Introduction to environmental toxicology: impacts of chemical upon ecological systems. Lewis Publishers.

10. Liu, W.; Zhu, L.S.;Wang, J.; Wang, J.H.; Xie, H.; Song, Y. (2009). Assessment of the genotoxicity of endosulfan in earthworm and white clover plants using the comet assay. Arch. Environ.Contam.Toxicol. 56, $742-746$.
11. Lopes, P.R.M.; Bidoia, E.D. (2009). Evaluation of the biodegradation of different types of lubricant oils in liquid medium. Braz. Arch. Biol.Techn. 52 (5), 1285-1290.

12. Lopes, P.R.M.; Montagnolli, R.N.; Domingues, R.F.; Bidoia, E.D. (2010). Toxicity and biodegradation in sandy soil contaminated by lubricant oils. Bull. Environ. Contam.Toxicol. 84 (4), 454-458.

13. Montagnolli, R.N.; Lopes, P.R.M.; Bidoia, E.D. (2009). Applied models to biodegradation kinetics of lubricant and vegetable oils in wastewater. Int. Biodeter. Biodegr. 63, 297-305.

14. OECD - Organization for Economic Cooperation and Development 1984. Guideline for testing of chemicals $n^{\circ} 207$ : earthworms, acute toxicity test. OECD, Paris.

15. Pagga, U. (1997). Testing biodegradability with standardized methods. Chemosphere. 35 (12), 2953-2972.

16. Paumgartten, F.J.R. (1993). Risk assessment for chemical substances: the link between toxicology and public health. Cad. Saúde Públ. 9 (4), 439-447.

17. Pinto, A.C.; Guarieiro, L.L.N.; Rezende, M.J.C.; Ribeiro, N.M.; Torres, E.A.; Lopes, W.A.; Pereira, P.A.P.; Andrade, J.B. (2005). Biodiesel: an overview. J. Braz. Chem. Soc.16 (6B), 1313-1330.

18. Ramalho, V.C.; Jorge, N. (2006). Antioxidantes utilizados em óleos, gorduras e alimentos gordurosos (Antioxidants used in oils, fats and fatfoods). Quim. Nova. 29 (4), 755-760.

19. Schleicher, T.; Werkmeister, R.; Russ, W.; Meyer-Pittroff, R. (2009). Microbiological stability of biodiesel-diesel-mixtures. Biosci. Biotechnol. 100, 724-730.

20. Wang, W.; Keturi, P.H. (1990). Comparative seed germination tests using ten plants species for toxicity assessment of metal engraving effluent samples. Wat., Air, Soil. Pollut. 52, 369-376. 